\title{
PSICOSSOMÁTICA NO COTIDIANO INFANTIL
}

\author{
Claudio João Paulo Saltini ${ }^{1}$
}

SALTINI, C. J. P. Psicossomática no Cotidiano Infantil. Rev. Bras. Cresc. Des. Hum. 1(2): 1991.

\section{RESUMO}

Este artigo identifica as relações entre as doenças, 0 somático e 0 simbólica. Partindo do princípio de que o homem é um animal sirnbólico, são analisados os mecanismos que conduzem à formação desses simbolos, atividade do próprio eu tentando lidar com as ansiedades provocadas por sua relação com os objetos. Quando a simbolização não se processa, o desenvolvimento do ego pode ser extremamente prejudicada, gerando complicações ao nível do somático.

Ao decifrarmos as complexas ligações entre o soma e o símbolo, conseguiríamos penetrar no inconsciente do ser humano, aliviando as energias responsáveis pelo mau somático. O resultado seria então a cura no campo psicossomático. Procuramos demonstrar que, em muitos casos, a palavra e a descoberta das causas que inibiram a estruturação dos simbolos podem, mesmo sem o apoio de uma terapêutica farmacológico, conduzir a resultados positivos.

\section{ABERTURA}

Este trabalho divide-se em três partes. Uma apresentação teórica, um caso clínico e algumas discussões. Normalmente, o caso clínico é apresentado no final para reforçar uma teoria. Estarei, no entanto, invertendo esta sequência, com a proposta de avaliar como a psicossomático pode elucidar fenómenos do desenvolvimento humano.

Um paciente, um menino de 11 anos, me procura juntamente com seus- pais. É uma criança com péssimo desempenho escolar e extremamente tímida. Apresenta psicomotricidade lenta, quase hipotônica. Não pratica esporões, é desajeitado e não gosta do próprio corpo. Em casa, esta criança demonstra interesse por pequenas animais. Escondido dos pais, pratica certos sadismos, como tirar as asas das moscas para ver o que acontece, colocar os animais na geladeira e outras experiências do género. No consultório, evita olhar nos meus olhos. Observo uma insis- tente palidez, sugerindo anemia. Posteriormente, exames clínicos confirmam a suspeita.

Feita a anamnese, começo a trabalhar com a criança em ludoterapia $\mathrm{O}$ trabalho com a mãe é iniciado separadamente. Após alguns meses, é possível perceber neste menino uma agressividade escamoteada, projetada sobre a mãe. E a mãe confirma: a criança tem medo, acorda à noite para se certificar de que ela está no quarto, que não está morta.

Decorrido certo tempo, o menino, que nunca havia desenhado, me apresenta um desenho, um avião que, segundo ele, transportava pessoas. Em outra sessão, surge um barco, símbolo que desde a Mesopotamia vem sendo interpretado como o corpo que transporta a alma. Um barco dentro da água poderia ser uma simbologia primitiva dessa criança se colocando, mostrando seu corpo. Um terceiro desenho revela uma casa, à beira de um barranco. Ao lado da casa, um lago e duas árvores. A interpretação conduz a alusão à mãe, ao lago como reminiscência do líquido amniótico. Nas árvores, a tendência de querer subir, crescer, viver.

1 Membro-fundador e ex-presidente do CDH. Psicanalista e educador - Rua Mário Reis, 170 - Granja Viana - São Paulo - SP. 


\section{OS DESENHOS CONDUZEM A INTERPRETAÇÕES FUNDAMENTAIS SOBRE O QUADRO DA CRIANÇA}

Em outro momento, surge um barquinho, puxado por uma criança, e uma casa no barranco, caindo. Quando verbalizo sua agressividade, quando faço associações entre o desenho e a mae, a criança contesta: "Não, a casa não tem nada a ver com a minha

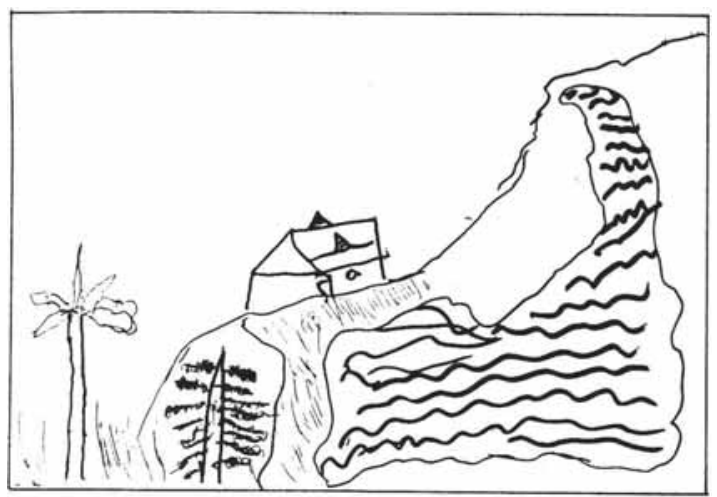

Figura 1- Gradativamente, os desenhos decifram a relação com a mãe, as ansiedades, os temeres e as expectativas da criança.

mãe. Mas tenho medo de que minha mãe seja assaltada, que ela caia e se machuque. Gostaria de protegê-la”. Novos contaras novos desenhos. Um avião bombardeado. Entendo como um bombardeio aos glóbulos verrnelhos. Agressividade voltada para o próprio sangue.

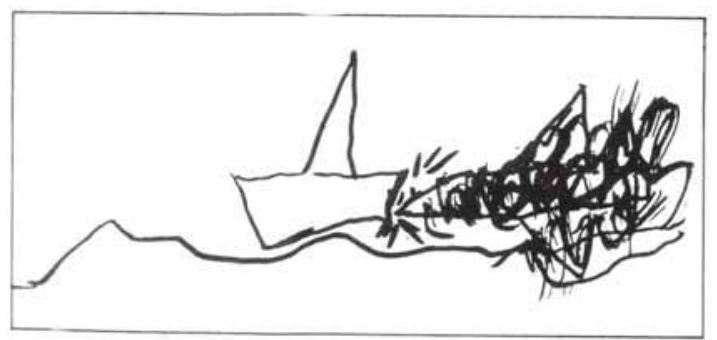

Figura 2- O "bombardeio", colorido de vermelho indica uma agressividade voltada ao próprio corpo. Ataque aos glóbulos vermelhos.

As sessões evoluem em torno dos desenhos. Estamos diante de um avião, inteiramente bombardeado, que bate em um barco levando-o ao fundo do rio. Depois vem um submarino e a criança me diz: "Ele está saindo da água, vai respirar, encher seus tanques de oxigênio". Prossigo em direção à sua história, procurando detectar outras descobertas sobre a respiração fora da água.

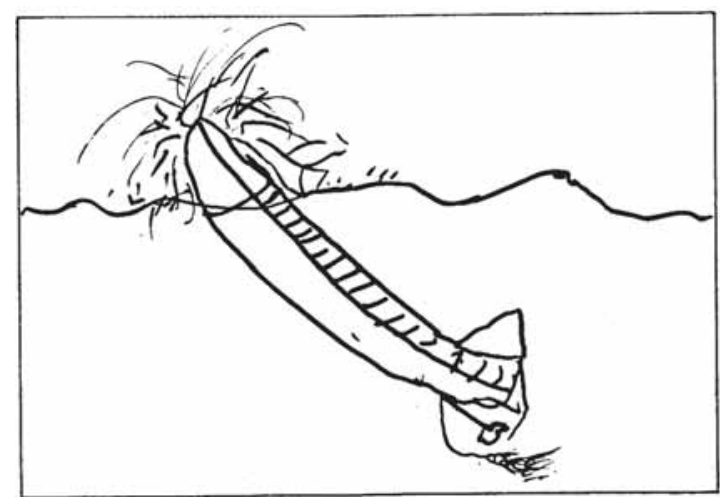

Figura 3 - O submarino, a criança, começa a se expor, a sair da água em busca de ar, de nova carga de oxigênio.

Nas terapias seguintes, ele deixa de apresentar quadros isco lados para construir histónas: Daqui está um pássaro voando livremente, ele vê a água e o mundo todo lá embaixo. E aqui estão as ervas para ele se alimentar. O pássaro pausa em uma árvore e encontra uma cobra”. Num próximo desenho, o pássaro pega a cobra com o bico, mata a cobra e decide ansport la. Concluo que esta cobra tem um primeiro momento naquele avaro isolado e sozinho, que aos poucos ganha sentido. O barco, 0 pássaro é ele, agora voando, encontrando uma maneira de alimentar os filhotes.

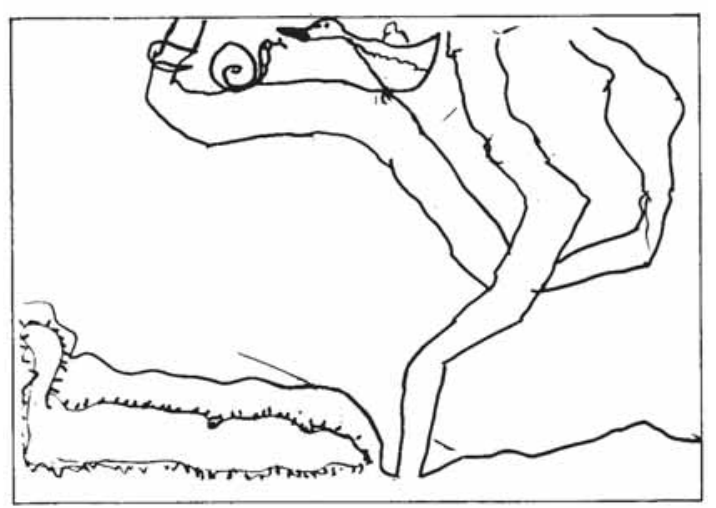

Figura 4 - O passará a cobra assinalam a evolução de lona nova Á, caracterizada pela transformação simbólica da cnança.

\section{AGRESSIVIDADE TRABALHADA, TRANSFORMADA EM FONTE E PRODUÇÃO DE VIDA}

Nesta fase, pode-se registrar a transformação simbólica, totalmente inconsciente desta criança. Ela transforma a agressividade em produçao de vida, de sustentação dos filhos, de 
metabolização dos alimentos. O cantata evolui para outros quadros bise ricos: um tigre descendo de uma árvore e uma vaca. O menino diz: "O tigre vai comer a vaca”. Margem para novas interpretações, frutos de teorias profundas, mas, sem dúvida, distantes do real absoluto. Identifico uma volta à agressividade, agora ar malizada. Agressividade passável de ser elaborada por nós mesmos. Posso ser feroz desde que o tigre vá em busca de uma vaca. Pergunto se o tigre comeu a vaca. "Sim, porque esta é a lei da vida. As vezes, é preciso comer a vaca para sobreviver, o tigre não faz por mal”. Assim se $m a^{\wedge} \wedge \wedge$ lifesta essa criança que vai muito mal na escola. Registo uma elaboração já ao nivel do pré-consciente, onde ela explica os aspectos de sua agressividade. A agressão pode servir à vida.

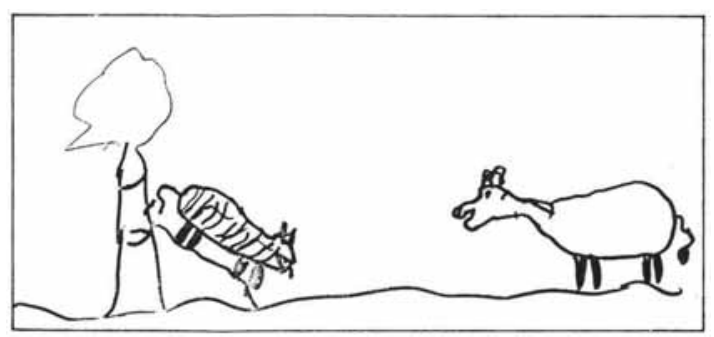

Figura 5 - A vaca é o alimento do tigre. A agressividade adquire um novo sentido, passando a servir à vida.

Passado um ano de terapia, a anerma desaparece, a criança apresenta condições para ser aprovada na escola e se posiciona perante os colegas que antes ridicularizavam seu comportamento: "Gostaria que vocês me respeitassem, assim como respeito vocês. Não gosto que vocês me gozem, isso me da mal-estar".

\section{DE QUE FORMA O SIMBOLO ESTÁ RELACIONADO AO SOMA}

Neste caso, a palavra, mesmo sem o apoio de uma terapêutica somático, deu resultado. Tenciono discutir como o símbolo está relacionado ao soma. O que é uma leitura? Naturalmente, leitura implica em comunicação. Então, o que é leitura e o que é comunicação?

Nossa percepção é aguçada através de palavras, de objetos. Mas, como esses elementos aluam dentro de nós? Poderíamos, inicialmente, pensar no que Pavlov identifica como estímulo e resposta. Vamos partir de um exemplo. Temos em mãos um pedaço de carne e um sino. Diante deles, um cachorro que saliva diante da carne, respondendo biologicamente ao objeto. A salivação é uma leitura primitiva do objeto carne. Se jun- tarmos a carne e o sino, apresentando-os simultaneamente ao animal, veremos que, num terceiro momento, ao mostrar apenas o sino, ele também vai salivar; Ou seja, o cachorro fará uma leitura deste sino condicionado. O fenómeno é tão importante que fundamenta toda uma escola de psicologia - a reflexologia-, estendendo sua influência a praticamente todos os estudos até hoje realizados na área da educação.

Piaget questiona esses princípios, considerando exagero atribuir tudo ao condicionamento. No primeiro instante da leitura, identificamos um sinal. O segundo tipo de leitura está muito ligado ao sinal, mas não é arbitrária É a leitura por índice: frente a um objeto imaginamos aquilo que ele pode representar, aquilo que pode nos dar como complemento de sua totalidade.

\section{AADEQUAÇÃO É FRUTO DA ESTRUTURA COGNITIVA E DE EXPERIENGIAS PRÉVIAS}

Acredito que as leituras são submissos às estruturas mentais que possuímos no momento em que estamos lendo aquele determinado objeto. A leitura de uma criança diante de uma escada seria a manifestação da necessidade do corpo agir sobre o objeto. É claro que, nessa situação, há duas formas de reação. Se ela não souber subir escadas, vai tentar por ensaio e erro, testando sua coordenação motora. Se, ao contrário, esta criança souber subir escadas, vamos concluir que ela conhece o objeto. Porque? Porque o corpo reage adequadamente frente ao objeto. Da mesma forma, a leitura do adulto diante de uma determinada situação seria o comportamento adequado a essa circunstancia. A adequação é fruto de uma estrutura cognitiva e de experiências prévias.

Uma criança ao presenciar o ato sexual de seus pais não vê um ato sexual. Sua estrutura mental e afetiva não está preparada para ter esse tipo de visão e de leitura. A percepção sugere uma briga entre o pai e a mãe. Em uma fase posterior, as próprias crianças verbalizam essa sensação, relatando brigas onde o pai sacrificava a mãe, provocando dores e sofrimento. O real, a tota lidade, são, portanto, uma construção da mente. Ortega e Gasses afirmavam: "Ao olharmos uma laranja, não estamos vendo uma laranja. Estamos vendo a metade de uma laranja, a outra metade está construída dentro do nosso cérebro. E não só a outra metade, mas a totalidade, a parte interna das células desta laranja”. Essas considerações são de extrema importância quando estamos diante de um ser humano, pluralista, rico em "metades". 
Há uma terceira forma de ler, e essa nos interessa mais a Um chapéu de cowboy, por exemplo, escondido atrás fundo. Ler através de um símbolo, concentração de uma única de uma pedra poderia sugerir que lá está um homem, um cowimagem de idéias e sentimentos diversos. O homem é um animal boy, Esta seria uma outra espécie de leitura, obtida através de simbólica. Por que? Porque no primeiro instante de sua vida um índice capaz de sugerir uma situação global. As represen- investe em objetos que causam prazer ou desprazer, chamados de tações são construções internas provenientes das ações e das mãe, seio, seio parcial, pessoa ou sujeito parcial. Há um investipercepções diante do mundo. A percepção traz informações mente altíssimo de abeto no objeto mãe proporcionando sensações referentes ao índice, às ações possíveis sobre o objeto. Interae registros afetivos. dos, os dois planos conduzem a uma representação, presente.

Portanto, na frente de alguma coisa temos sempre, de um em nossa mente, e acionada, quando necessário, por um índice lado, o investimento energético e, de outro, uma sensação interna agradável. Neste instante, estamos satisfazendo nossas necessidados de aconchego, de alimento. O símbolo forma-se, então, porque, aos poucos, esses objetos vão sendo eliminados. A mãe vai se subtraindo, nos frustrando e, em consequência, precisamos criar objetos internos, construir estruturas prontas para, de uma certa forma, substituir a ausência. Este trabalho é feito pelo nosso inconsciente, o eu, intimamente ligado a nós, ao soma, ao prazer e à própria vida.

\section{OS SÍMBOLOS CARREGAM OS COMPONENTES DOS OBJETOS LENTAMENTE SUBTRAÍDOS}

Sfmbolo é todo o signo natural. Simbolos não surgem de vinculações arbitrárias, carregam os componentes do seu referencial ou do objeto que vai desaparecendo. Enfatizo que existe sempre uma razão afetiva, um investimento energético aplicado ao objeto primário. O inconsciente é um lugar psíquico especial que deve ser concebido não como uma segunda consciência, mas como um sistema munido de conteúdos, mecanismos e energia específicos. É, principalmente, o lugar onde estao os conteúdos ausentes no campo da consciência, conteúdos esses quase sempre reprimidos. Reprimidos porque os objetos se vão e deixam a dor e o sofrimento, porque os conflitos nos obrigam a abandonar nossos desejos, porque os corpos de nossos pais, ponto de descarga de energias afetivas, um dia se afastam, nos deixan- do sozinhos. A falta de um objeto precisa ser reprimida pelo seu próprio sofrimento. A partir desta matéria-prima surge, na fábrica do inconsciente, o sfmbolo como produto que, socializado, transforma-se em palavra ou signo. Assim, o signo passa a ser um elemento que leva o símbolo no seu bojo. Não há signo sem símbolo, mas, evidentemente, poderá haver um símbolo sem signo, sem palavra.

Partindo desses pressupostos, acredito que, ao trabalhar com a palavra, conseguiríamos atingir o símbolo; o símbolo atingiria o índice e o índice chegaria ao sinal. Poderíamos chegar ao amago das coisas, ao soma, ao centro orgânico. Em termos psicológicos, o simbolismo seria uma relação entre o ego, um objeto e um símbolo. A formação de simbolos é uma atividade do próprio ego, tentando lidar com as ansiedades mobilizadas por sua relação com os objetos, geradas pelo medo dos objetos, pelo medo da perda, pelos objetos ruins e dificuldades de acesso aos objetos bons.

\section{QUANDO A SIMBOLIZAÇÃO NÃO SE PROCESSA, O DESENVOLVIMENTO DO EGO É PREJUDICADO}

Os simbolos representam idéias de um eu, do sela, das relaçôes sanguíneas imediatas, dos fenómenos relacionados ao nasc ento, à vida e à morte. O simbolismo surge como resultado do conflito intraps quico entre as tendências repressoras e o reprimido. Somente o que é reprimido precisa ser simbolizado. Os primeiros impulsos de uma criança estão direcionados, segundo Melanie Klein, para os corpos de seus pais e para seu próprio corpo. No inconsciente, esses objetos de impulso despertam outros interesses pela vida e, principalmente, pela via de simbolização.

Para enriquecer estas conexões teóricas com o caso inicialmente exposto, gostaria de citar Melanie Klein. Em 1930, ela detecta um problema de inibição na formação de simbolos e relata a história de um menino de quatro anos, chamado Dick, autista, que não conseguia falar ou brincar, não demonstrava afeto e não se interessava pelas coisas à sua volta, exceto por trincos de portas e estações de trem. A análise revelou que a criança estava putrificada pelo medo de sua agressão em relação ao corpo da mãe e ao seu próprio corpo. Ela sentia que 0 corpo da mãe se tornara mal em função de seus ataques a ele. Em razão do peso de suas ansiedades, ele erguera defesas poderosas contra suas fantasias a respeito dela. O resultado foi a estagnação na formação 
de simbolos e, consequentemente, na estrutura cognitiva dessa criança. Ela não dotara o mundo que a cercava de significado simbolico, cognitivo ou epistêmico e, portanto, não registrava qualquer interesse por esse mundo. De acordo com Melanie Klein, quando a simbolização não se processa, o desenvolvimento do ego sofre uma parada praticamente completa.

Em resumo, se nós temos um objeto e esse objeto vem sendo reprimido por sua ausência, ele deveria retornar pela via simb61ica, gerando uma representação cog^liitiva e, consequentemente, uma interação com o mundo habitado pelo indivíduo. Mas, se os objetos reprimidos, que deveriam voltar normalmente pelo campo da linguagem e da cognição, foram mal elaborados, seriam poucas as suas possibilidades de volta a este nfvel da consciência Terfamos então, uma elaboração inconsciente, sobrecarregada, que buscaria outros caminhos para conseguir simbolizar. O indivíduo usaria um órgão de seu corpo e, afetando esse órgão, emitiria uma espécie de mensagem ao mundo que o rodeia.

\section{BIBLIOGRAFIA}

1. GIACONIA, G. \& RACALBUTO, A. I percorri del Simbolo. Milano, Raffaello C. Editore, 1990.

2. BOCCHI, G. \& CERUTI, M. Disordine e Construcione. Milano, Feltrinnelli Editore, 1981.

3. PIAGET, J. A Formacão do Símbolo na Criança. Rio de Janeiro, Zahar Editores, 1978.

4. KLEIN, M. \& RIVIERE, J. Amor, Ódio e Reparação. São Paulo, Imago Editora, 1975.
Haveria um agravamento para o campo do psicossomático, ele estaria dizendo ao mundo que poderia ser entendido pelo campo dos sintomas e pela deformidade que este órgão sofreria.

Se nós, novamente no campo da consciência e não do somático, conseguirmos penetrar neste inconsciente, esvaziando e organizando a carga energética responsável pelo mal no campo somático, teríamos condições de obter uma cura psicossomático.

Boa parte das doenças, estariam, desta maneira, relacionadas ao campo simbólica. Para finalizar, relembro uma afirmação de Freud: "Que o sintoma somático intervém na conversão simbólica, que o órgão fala e que tanto a linguagem como o sintoma extraem suas matérias-primas de uma mesma fonte, o inconsciente. E que, o concomitante somático por oposição à própria consciência psicológica não é outra coisa senão o psíquico inconsciente”. Lembro também que entre os psicóticos praticamente não há doenças, como o câncer, por exemplo.

5. KLEIN, M.; HEIMANN, P.; ISAACS, S. \& RIVIERE, J. Os Progressos da Psicanálise. Rio de Janeiro, Zahar Editores, 1978.

6. KLEIN, M. O Sentimento de Solidão. São Paulo, Imago Editora, 1975.

7. Contribuição à Psicanálise. São Paulo, Editora Mestre Jou, 1981. 8. Psicanàlise da Criança. São Paulo, Editora Mestre Jou, 1981.

9. CHIOZZA, L. A. Idéias para una Conception Psicoanalítica del Cancer. Buenos Aires, Editorial Paidos, 1978.

10 Psicoanálisis: Presente y Futuro. Buenos Aires, Edición del CIMP, 1983. 